\title{
Equal Efficacy of Glucoprotamin and an Aldehyde Product for Environmental Disinfection in a Hematologic Transplant Unit: A Prospective Crossover Trial
}

\author{
Ruth Meinke, MSc; ${ }^{1}$ Bernhard Meyer, PhD; ${ }^{2}$ Reno Frei, MD; ${ }^{1}$ Jakob Passweg, $M D ;{ }^{1}$ Andreas F. Widmer, MD, MS
}

\begin{abstract}
BACKGROUND. The inanimate hospital environment has emerged as an important reservoir of nosocomial pathogens. In particular, multidrug-resistant pathogens, such as methicillin-resistant Staphylococcus aureus, Acinetobacter species, and Clostridium difficile, play a major role in the transmission of hospital-acquired infections. In Europe, aldehydes, chlorine, and quaternary ammonium compounds have been commonly used for environmental disinfection. Glucoprotamin, a newer active compound for disinfectants, has been clinically tested for disinfection of instruments but not for environmental disinfection.
\end{abstract}

OBJECTIVE. This study evaluated the antimicrobial effectiveness of a glucoprotamin-containing product (Incidin) compared with that of an aldehyde-containing product (Deconex), the current standard at our institution.

METHODs. This prospective crossover study was conducted in our access-restricted hematologic transplant unit. A total of 3,086 samples from the environment were processed and examined for overall bacterial burden as well as selectively for S. aureus, C. difficile, and gramnegative bacteria.

RESUlTs. There was no significant difference in residual bacteria after disinfection between the 2 products in terms of overall burden and selected pathogens. Enterococci were the predominant pathogens recovered from surfaces, but no vancomycin-resistant enterococci were recovered. Similarly, $C$. difficile could not be found in the patients' environment, even in rooms, despite the use of selective media.

CONCLUSION. The aldehyde-containing product (Deconex) and the glucoprotamin-containing product (Incidin) demonstrated similar efficacy against environmental contamination in a hematologic transplant unit with the application of selective media for C. difficile, S. aureus, and gram-negative bacteria in addition to standard medium.

Infect Control Hosp Epidemiol 2012;33(11):1077-1080

The inanimate hospital environment has been identified as an important reservoir of nosocomial pathogens. ${ }^{1,2}$ The environment of a patient's room becomes contaminated especially in situations when patients suffer from infections with methicillin-resistant Staphylococcus aureus (MRSA) or vancomycin-resistant enterococci (VRE). Environmental cleaning has experienced a renaissance in recent years as a measure to reduce healthcare-acquired infections. ${ }^{3}$ The role of routine surface disinfection of all parts of a hospital has been debated controversially in the past. ${ }^{4}$ Routine surface disinfection has been recommended for high-risk settings. ${ }^{5}$ Traditionally, aldehydes as broad-spectrum microbicides have been used for surface disinfection, especially in Europe. Glucoprotamin has been introduced as an active compound (AC) for aldehydefree disinfectants. ${ }^{6}$ Unlike aldehydes, it does not evaporate, and it has shown good in vitro efficacy against multidrugresistant clinical strains ${ }^{7}$ and has performed well in tests for medical instruments. ${ }^{8}$
However, in-practice data for surface disinfection are lacking. Therefore, we initiated a crossover study to evaluate the effectiveness of Incidin (which contains glucoprotamin) relative to the current standard, Deconex (which contains aldehyde), in a high-risk clinical setting.

\section{METHODS}

\section{Setting}

The study was conducted at the hematologic transplant unit of the University Hospital Basel, Basel, Switzerland. Approximately 70 patients a year undergo stem-cell transplantation or high-dose chemotherapy with prolonged neutropenia, with an average stay of 4-6 weeks. Access is restricted. All rooms are single rooms and are provided with HEPA-filtered air, and healthcare workers wear protective clothing. The composition of the floor of the ward is $\mathrm{PVC}$, and bathrooms are tiled. 


\section{Study Design}

The study was a prospective crossover study conducted from October through December 2010. The study unit was split into 2 equal parts: one part was disinfected using aldehydecontaining disinfectant (Deconex), while the other was allocated to a glucoprotamin-containing disinfectant (Incidin). The first part of the study lasted 4 weeks. Before switching products, a washout phase of 1 day was performed using a detergent. After this cleaning, the 2 disinfectants were used crossover for another 4 weeks.

\section{Disinfectants and Disinfection Regime}

The aldehyde-containing disinfectant (Deconex $50 \mathrm{FF}$; Borer Chemie) contained $12.0 \mathrm{~g}$ of glyoxal (ethanedial), $0.5 \mathrm{~g}$ of glutaraldehyde (pentanedial), and $7.5 \mathrm{~g}$ of didecyldimethylammoniumchloride per $100 \mathrm{~g}$. The glucoprotamin-containing disinfectant (Incidin PLUS; Ecolab) contained $26 \mathrm{~g}$ of glucoprotamin per $100 \mathrm{~g}$. The concentration recommended by the manufacturer for hospital use for a 1-hour exposure was $0.5 \%$.

The disinfectants were freshly prepared in the morning, and all touch surfaces and floors in the patient rooms were disinfected daily with the corresponding disinfectant. The unit has a designated cleaning staff, and the majority of the housekeeping personnel have been working for more than 5 years in this unit.

Hospital policy requires the use of a disinfectant active against spores when Clostridium difficile polymerase chain reaction ribotype 027 is isolated. ${ }^{9}$ Rooms given this treatment were excluded from the study.

\section{Sampling and Incubation}

Sampling sites in rooms were as follows: the table used by staff (sample size, $10 \times 10 \mathrm{~cm}$ ), the electric bed control panel (whole surface, approximately $5 \times 10 \mathrm{~cm}$ ), the cold water faucet in the patient's bathroom (sphere, diameter of $5 \mathrm{~cm}$ ), the table used by the patient (sample size, $10 \times 10 \mathrm{~cm}$ ), and the floor close to the patient's bed (sample size, $10 \times 10$ $\mathrm{cm})$. Sampling was done every other day in the morning after disinfection. The time between disinfection and sampling was recorded. The sampling sites were swabbed with premoistened $(0.9 \% \mathrm{NaCl})$ swabs (Unomedical). Swabs were vortexed in $2 \mathrm{~mL}$ of neutralizing solution, and $0.2 \mathrm{~mL}$ was plated on each medium.

The neutralizing solutions were validated for both disinfectants, and nontoxicity was proved. The following neutralizing solutions were used as recommended by the manufacturers: for Deconex (aldehyde), 3\% Tween 80, 3\% saponin, $0.1 \%$ histidine, and $0.1 \%$ cysteine; and for Incidin (glucoprotamin), 3\% Tween 80, 3\% saponin, 0.3\% lecithin, $0.1 \%$ histidine, and $0.5 \%$ sodium thiosulfate.

\section{Microbiology}

The following media were used: Columbia agar (Becton Dickinson) with $5 \%$ sheep blood for total colony count,
CHROMAgar orientation medium (Becton Dickinson) for gram-negative bacteria, BBL CHROMAgar S. aureus (Becton Dickinson), and Clostridium agar CLO (bioMérieux) for $C$. difficile. Incubation details were as follows: $36^{\circ} \mathrm{C}$ for 48 hours; for Columbia agar, $\mathrm{CO}_{2}$ atmosphere; and for Clostridium agar, anaerobic conditions.

\section{Molecular Typing}

All strains of Pseudomonas aeruginosa, C. difficile, MRSA, and other multidrug-resistant pathogens were characterized by molecular typing (pulsed-field gel electrophoresis [PFGE]).

\section{Statistical Analysis}

Data were entered into a spreadsheet (Excel; Microsoft) and then imported into SPSS 19. Univariate analysis was performed using the $\chi^{2}$ test or the Fisher exact test, where appropriate, for categorical variables and the 2-tailed Student $t$ test or the Kolmogorov-Smirnov test for continuous variables. Differences with $P<.05$ were regarded as statistically significant.

\section{RESULTS}

Of a total of 3,068 analyzed samples obtained, 1,528 were from surfaces disinfected with Deconex (AC aldehyde), and 1,540 were from surfaces disinfected with Incidin (AC glucoprotamin). One hundred fifty-two (9.9\%) samples from aldehyde-disinfected surfaces and $185(12.0 \%)$ samples from glucoprotamin-disinfected surfaces showed growth $(P=$ $.067)$. The bacterial counts on positive environmental sites were not statistically different $(P=.58$; Table 1$)$ for both tested products.

Gram-negative bacteria were found in 1 sample (Enterobacter aerogenes), from a floor treated with Incidin (6 colonyforming units [CFUs] $/ 100 \mathrm{~cm}^{2}$ ). P. aeruginosa was found on a faucet. This strain was identical with a patient's isolate from rectal screening, confirmed by identical PFGE pattern. However, there was no evidence for $P$. aeruginosa infection.

$S$. aureus was isolated twice from floors disinfected with Deconex as well as twice from a floor, twice from a bed control panel, and once from a water faucet disinfected with Incidin. C. difficile was not detected in any samples, despite the fact that clinical cases occurred during the study and that selective culture medium was used.

Enterococci (E. faecalis and E. faecium) were the most frequently encountered pathogens, detected in 3\% (glucoprotamin disinfection, $n=328$ ) and $6 \%$ (aldehyde disinfection, $n=290)$ of all environmental samples $(P=.14)$. High numbers (up to $8,000 \mathrm{CFUs} / 100 \mathrm{~cm}^{2}$ ) of enterococci could be detected even shortly after disinfection $(60 \mathrm{~min})$.

\section{DISCUSSION}

No significant difference in the antimicrobial effectiveness between the commonly used Deconex (AC aldehyde) and Incidin (AC glucoprotamin) was found (Table 1), despite the 
TABLE 1. Bacterial Counts on Positive Environmental Sites after Surface Disinfection

\begin{tabular}{|c|c|c|c|c|c|}
\hline \multirow[b]{2}{*}{ Sample site } & \multicolumn{2}{|c|}{ Deconex (AC aldehyde) } & \multicolumn{2}{|c|}{ Incidin (AC glucoprotamin) } & \multirow[b]{2}{*}{$P$} \\
\hline & $\begin{array}{c}\text { CFUs } / 100 \mathrm{~cm}^{2} \\
\text { mean } \pm \operatorname{SD}\left(n=61^{\mathrm{a}}\right)\end{array}$ & $\begin{array}{l}\% \text { negative } \\
\text { samples }\end{array}$ & $\begin{array}{c}\text { CFUs/100 } \mathrm{cm}^{2}, \\
\text { mean } \pm \mathrm{SD}\left(n=67^{\mathrm{a}}\right)\end{array}$ & $\begin{array}{l}\% \text { negative } \\
\text { samples }\end{array}$ & \\
\hline Overall & $645 \pm 1,387$ & 46 & $1,729 \pm 4,890$ & 53 & $.580^{\mathrm{b}}$ \\
\hline Staff table & $51 \pm 300$ & 74 & $1,642 \pm 12,217$ & 46 & .290 \\
\hline Bed control panel & $13,220 \pm 33,995$ & 53 & $6,483 \pm 23,874$ & 60 & .201 \\
\hline Water faucet & $11,480 \pm 32,134$ & 57 & $7,478 \pm 26,472$ & 57 & .446 \\
\hline Patient table & $158 \pm 1,022$ & 59 & $1,828 \pm 12,252$ & 47 & .270 \\
\hline Floor & $325 \pm 638$ & 26 & $713 \pm 2,578$ & 25 & .237 \\
\hline
\end{tabular}

NOTE. AC, active compound; CFU, colony-forming unit; $\mathrm{SD}$, standard deviation.

${ }^{a}$ Quantitative cultures analyzed.

b $P=.075$ for negative samples.

large sample size. Several studies have not been able to show a difference between thorough cleaning with a detergent and cleaning with a disinfectant. ${ }^{4,5,9,10}$ Recolonization shortly after disinfection was documented by Dharan et al, ${ }^{4}$ who postulated the need for disinfection of patients' environments more frequently than once daily. However, these studies did not use selective media to detect clinically important pathogens.

While it is obvious that the inanimate environment can be a source of nosocomial pathogens, clear guidance on the limits of microbial contamination of inanimate surfaces in hospital settings is lacking. Dancer ${ }^{10}$ suggested a limit of less than $5 \mathrm{CFUs} / \mathrm{cm}^{2}$ for frequent hand-contact surfaces in hospitals. ${ }^{11}$ In our study, we found results exceeding this limit even 60 minutes after disinfection, especially on the floor and on sites near patients (patient table and bed control panel).

Some limitations to this study should be mentioned. A standardization of sampling times was not feasible. However, our study design using multiple time points allowed us to show recontamination of the environment over time. Although patients are exposed to their environment 24 hours a day, routine surveillance could not document a clinical infection from the environmental source. In contrast, a patient infected with $S$. aureus contaminated his environment in 3 samples (floor and bed control panel).

No gram-negative bacteria were detected from the environment, except for 1 strain of $E$. aerogenes. Of the positive clinical patient specimens obtained on the ward, $21 \%$ showed gram-negative bacteria (data not shown); however, we could not identify Escherichia coli or Klebsiella species from the environment. This might be due to the short survival times of some of the gram-negative bacteria ${ }^{1}$ and to the stringent and thorough daily cleaning regimen.

One patient had toxin-positive $C$. difficile diarrhea during the study, potentially exposing the environment. ${ }^{12}$ However, none of the environmental samples revealed $C$. difficile despite the use of selective culture medium. Neither disinfectant has sporicidal efficacy under the conditions applied in this study. A good subjective cleaning efficacy of both products was reported by the cleaning staff and in combination with the stringent and thorough daily cleaning regimen may have contrib- uted to the absence of $C$. difficile. In fact, thorough cleaning without a disinfectant can remove more than $95 \%$ of spores. ${ }^{10,13}$ However, these data call into question whether sporicidal activity is required in a nonepidemic setting, ${ }^{14}$ and further research would certainly be needed to explain these findings. ${ }^{15}$

Enterococci were isolated from the environment even shortly after disinfection, as already observed by Weber and Rutala $^{16}$ and Anderson et $\mathrm{a}^{17}$ for VRE. A stricter adherence to disinfection protocols was therefore recommended by Anderson et al. ${ }^{17}$ VRE are becoming more and more problematic in hospitals and cause epidemic outbreaks, even though not all VRE are associated with outbreaks. ${ }^{17}$ The frequent isolation of enterococci after disinfection may be due to recontamination or emergence of resistance to the disinfectant. In $3 \%$ of clinical specimens from the ward, enterococci were found; no VRE were reported during the study period (data not shown). We have tested 3 strains according to EN 1040, ${ }^{18,19}$ and no evidence for resistance to Deconex or Incidin was found. Similarly, Anderson et $\mathrm{al}^{17}$ and Tyski et $\mathrm{al}^{7}$ could show that VRE were susceptible to a spectrum of hospital-grade disinfectants, and they could not find a link between resistance to vancomycin and germicides.

In summary, the aldehyde-containing product and the glucoprotamin-containing product demonstrated similar efficacy against environmental contamination in a high-risk hospital environment, despite the use of selective media for C. difficile, $S$. aureus, and gram-negative bacteria in addition to standard medium. C. difficile was not detected even though glucoprotamin is not active against spores, possibly because of daily cleaning by in-house staff.

\section{ACKNOWLEDGMENTS}

We thank Danica Nogarth for analyzing the samples and performing the microbiological tests.

Financial support. The study was supported in part by Ecolab, Düsseldorf, Germany. Ecolab had no influence on the design, conduct, and analysis of the study.

Potential conflicts of interest. B.M. is an employee of Ecolab. All other authors report no conflicts of interest relevant to this article. All authors 
submitted the ICMJE Form for Disclosure of Potential Conflicts of Interest, and the conflicts that the editors consider relevant to this article are disclosed here.

Address correspondence to Andreas F. Widmer, MD, MS, Division of Infectious Diseases and Hospital Epidemiology, University Hospital Basel, Petersgraben 4, 4031 Basel, Switzerland (awidmer@uhbs.ch).

Presented in part: 22nd European Congress of Clinical Microbiology and Infectious Diseases; London, United Kingdom; March 31-April 3, 2012 (Poster).

\section{REFERENCES}

1. Kramer A, Schwebke I, Kampf G. How long do nosocomial pathogens persist on inanimate surfaces? a systematic review. BMC Infect Dis 2006;6:130.

2. Widmer AF, Frei R. Decontamination, disinfection, sterilization. In: Murray PR, Baron EJ, Pfaller M, Tenover FC, Yolken R. Manual of Clinical Microbiology. Baltimore: American Society of Microbiology, 2011:138-164.

3. Dancer SJ, White LF, Lamb J, Girvan EK, Robertson C. Measuring the effect of enhanced cleaning in a UK hospital: a prospective cross-over study. BMC Med 2009;7:28.

4. Dharan S, Mourouga P, Copin P, Bessmer G, Tschanz B, Pittet D. Routine disinfection of patients' environmental surfaces: myth or reality? J Hosp Infect 1999;42:113-117.

5. Exner M. Divergent opinions on surface disinfection: myths or prevention? a review of the literature. GMS Krankenhhyg Interdiszip 2007;2:doc19.

6. Meyer B, Kluin C. Efficacy of glucoprotamin containing disinfectants against different species of atypical mycobacteria. $J$ Hosp Infect 1999;42:151-154.

7. Tyski S, Grzybowska W, Greszczuk S, et al. Antimicrobial activity of glucoprotamin-containing disinfectants. Pol J Microbiol 2009; 58:347-353.

8. Widmer AF, Frei R. Antimicrobial activity of glucoprotamin: a clinical study of a new disinfectant for instruments. Infect Control Hosp Epidemiol 2003;24:762-764.
9. Fenner L, Widmer AF, Stranden A, et al. First cluster of clindamycin resistant Clostridium difficile PCR ribotype 027 in Switzerland. Clin Microbiol Infect 2008;14:514-515.

10. Dancer SJ. How do we assess hospital cleaning? a proposal for microbiological standards for surface hygiene in hospitals. J Hosp Infect 2004;56:10-15.

11. Anderson RE, Young V, Stewart M, Robertson C, Dancer SJ. Cleanliness audit of clinical surfaces and equipment: who cleans what? J Hosp Infect 2011;78:178-181.

12. Dumford DM, Nerandzic MM, Eckstein BC, Donskey JC. What is on that keyboard? detecting hidden environmental reservoirs of Clostridium difficile during an outbreak associated with North American pulsed-field gel electrophoresis type I strains. Am J Infect Control 2009;37:15-19.

13. Dancer SJ. Hospital cleaning in the 21 st century. Eur J Clin Microbiol Infect Dis 2011;30:1473-1481.

14. Dancer SJ. The role of environmental cleaning in the control of hospital-acquired infection. J Hosp Infect 2009;73:378-385.

15. Struelens M, Maas A, Nonhoff C, et al. Control of nosocomial transmission of Clostridium difficile based on sporadic case surveillance. Am J Med 1991;91:138-144.

16. Weber DJ, Rutala WA. Role of environmental contamination in the transmission of vancomycin-resistant enterococci. Infect Control Hosp Epidemiol 1997;18:306-309.

17. Anderson RL, Carr JH, Bond WW, Favero MS. Susceptibility of vancomycin-resistant enterococci to environmental disinfectants. Infect Control Hosp Epidemiol 1997;18:195-199.

18. Tschudin Sutter S, Frei R, Dangel M, Gratwohl A, Bonten M, Widmer AF. Not all patients with vancomycin-resistant enterococci need to be isolated. Clin Infect Dis 2010;51:678-683.

19. Deutsches Institut für Normung. Chemical Disinfectants and Antiseptics-Quantitative Suspension Test for the Evaluation of Basic Bactericidal Activity of Chemical Disinfectants and Antiseptics-Test Method and Requirements (Phase 1). DIN EN 1040: 2006-03(E). Berlin: Beuth, 2006. 